\title{
Comparison of Evaporation Estimation Methods in Van Lake, Turkey
}

\author{
Abdulqadir Salih', Nermin Sarlakl² \\ ${ }^{1}$ University of Gaziantep, Turkey \\ ${ }^{2}$ Karamanoglu Mehmetbey University, Turkey \\ abdulqadirmsalih@hotmail.com; nsarlak@kmu.edu.tr
}

\section{Extended Abstract}

Van Lake in the eastern Anatolian high plateau of Turkey, is the largest soda lake in the world lies between coordinates $37^{\circ} 43^{\prime}-39^{\circ} 26^{\prime} \mathrm{N}$ and $42^{\circ} 40^{\prime}-44^{\circ} 31^{\prime} \mathrm{E}$. Since it is one of the worlds largest endorheic lakes (closed basin), the only outflow is evaporation. Evaporation is the unique in the sense that is influenced not only by climate, but also by characteristics of the lake itself (e.g. depth, area, colour/clarity etc.). Evaporation from lake is undesirable and unrecoverable, occurring often in large quantities especially in arid and semi-arid climates, understanding the physics of evaporation is very important. Although it is possible to measure the evaporation directly by using appropriate equipment like pan and eddy covariance, it is much more difficult and expensive than for precipitation and stream flow and is usually impractical. Hence, scientists have developed an array of methods that estimates of evaporation based on measurements of more readily measured quantities since last century. These methods are: water-budget, energy balance, so-called Dalton group such as the bulk aerodynamic or mass transfer, so-called combination group such as Penman among others. Advantages and limitations of these methods are discussed in particular Van Lake. The main goal of this study is to estimate evaporation from the Van Lake in existing approaches. Then, these results are compared to the results obtained from other researches as well as pan observation to find the appropriate estimation of evaporation approach for the Van Lake.

The analysis shows that Romanenko mass transfer evaporation formula is much more consistent with pan observation than the other approaches in the study area. Penman mass transfer and Dalton mass transfer approaches follow the Romanenko approach. Including wind velocity variable not seem to improve evaporation results. Results estimated from Romanenko formula were also compared with Erdemir (1999) results obtained from Combined Penman approach. A measure of goodness of fit $\left(\mathrm{R}^{2}\right)$ which indicates the present of variance was 0.77 . Therefore, Romanenko mass transfer formula seems to be utilized as an appropriate approach as a substitute for pan measurement to estimate evaporation of Van Lake.

\section{References}

[1] N. USUL, Engineering hydrology. Ankara, Turkey: Middle East Technical University, 2009.

[2] E. T. Degens and H. K. Kempe, "A geological study of Lake Van," vol. 15, pp. 305-319, 2001.

[3] M. T. Kavak, "Investigation Sea Surface Temperature variation of Lake Van," Dicle University, Turkey, 2011.

[4] A. Abdelrady, "Evaporation over fresh and saline water using SEBS," M.Sc. Thesis, University of Twente, The Netherland, 2013.

[5] A. T. White, "Estimation of surface water evaporation at Lake Lacawac," M.Sc. Thesis, Lehigh University, Pennsylvania, USA, 1997.

[6] S. Erdemir, "Determination of Evaporation of Lake Van using Meteorological Data," M.Sc. Thesis, Middle East Technical University, Turkey, 1999.

[7] V. P. Singh and C. Y. Xu, "Evaluation and generalization of 13 mass-transfer equations for determination free water evaporation," vol. 15, pp. 305-319, 2001. 